\title{
Investigation of the Effect of Canagliflozin on the Disposition Index, a Marker of Pancreatic Beta Cell Function, in Patients with Type 2 Diabetes
}

This article was published in the following Dove Press journal: Diabetes, Metabolic Syndrome and Obesity: Targets and Therapy

\author{
Mitsuyoshi Takahara $\mathbb{D}^{\prime}$ \\ Toshihiko Shiraiwa $\mathbb{D D}^{2}$ \\ Taka-aki Matsuoka $\mathbb{I D}^{3}$ \\ Kaoru Yamamoto $\mathbb{D}^{2}$ \\ Yoshifumi Maeno (D) ${ }^{2}$ \\ Yuka Shiraiwa $\mathbb{D}^{2}$ \\ Yoko Yoshida (iD $)^{2}$ \\ Naoto Katakami $\mathbb{D i D}^{4}$ \\ Hiroaki lijima (iD) ${ }^{5}$ \\ Hideyuki Katsumata ${ }^{6}$ \\ Kenji Arakawa ${ }^{5}$ \\ Toshio Hashimoto 5 \\ lichiro Shimomura $\mathbb{D D}^{3}$ \\ 'Department of Diabetes Care Medicine, \\ Osaka University Graduate School of \\ Medicine, Osaka, Japan; ${ }^{2}$ Shiraiwa Medical \\ Clinic, Osaka, Japan; ${ }^{3}$ Department of \\ Metabolic Medicine, Osaka University \\ Graduate School of Medicine, Osaka, \\ Japan; ${ }^{4}$ Department of Metabolism and \\ Atherosclerosis, Osaka University \\ Graduate School of Medicine, Osaka, \\ Japan; ${ }^{5}$ Ikuyaku. Integrated Value \\ Development Division, Mitsubishi Tanabe \\ Pharma Corporation, Tokyo, Japan; \\ ${ }^{6}$ Ikuyaku. Integrated Value Development \\ Division, Mitsubishi Tanabe Pharma \\ Corporation, Osaka, Japan
}

Correspondence: Taka-aki Matsuoka Department of Metabolic Medicine, Osaka University Graduate School of Medicine, 2-2 Yamadaoka, Suita, Osaka 565-087I, Japan

Tel $+81-6-6879-3732$

Fax +8I-6-6879-3739

Email matsuoka@endmet.med.osaka-u.ac. jp

Dobmit your manuscript $\mid$ www.dovepress.com
Aim: Our aim was to investigate the effects of add-on canagliflozin with glimepiride dose adjustment or glimepiride dose adjustment on pancreatic beta cell function in patients with type 2 diabetes mellitus and inadequate glycemic control despite stable triple therapy (metformin, teneligliptin, and glimepiride) plus diet/exercise therapy.

Methods: Forty patients on stable triple therapy were randomized to glimepiride dose adjustment without (glimepiride group) or with add-on canagliflozin $100 \mathrm{mg}$ (canagliflozin group) for 24 weeks. The glimepiride dose was adjusted every 4 weeks based on continuous glucose monitoring over the previous 2 weeks according to a prespecified algorithm. After the 24-week treatment period, the patients returned to the pre-intervention regimen for 1 week (wash-out period). Patients underwent $75 \mathrm{~g}$ OGTTs at the start of the run-in period and at the end of the wash-out period. The primary endpoint was the change in disposition index (DI).

Results: Thirty-nine patients completed the study (canagliflozin, $\mathrm{n}=19$; glimepiride, $\mathrm{n}=$ 20 ). The change in DI was $+5.1 \%$ and $-11.0 \%$ in the canagliflozin and glimepiride groups, respectively, with a between-group difference ratio of $18.0 \%(P=0.330)$. HbA1c, fasting plasma glucose, body weight, and daily-life continuous glucose monitoring-derived parameters improved in the canagliflozin group. Hypoglycemia occurred in $60 \%$ (44 episodes) and $70 \%$ (79 episodes) of patients in the canagliflozin and glimepiride groups, respectively. The change in DI was significantly correlated with the changes in glycemic control and variability in overall cohort.

Conclusion: Adding canagliflozin to the triple therapy improved beta cell function by $18 \%$, but it did not reach statistical significance. This study also demonstrated a correlation between the change in DI and glycemic control. As canagliflozin improved both glucose level and variability with relatively lower risk of hypoglycemia compared with glimepiride dose adjustment, adding canagliflozin to the triple therapy may be clinically beneficial.

Trial Registration: UMIN000030208/jRCTs051180036.

Keywords: beta cell function, canagliflozin, glimepiride, glycemic control, type 2 diabetes mellitus

\section{Introduction}

Type 2 diabetes mellitus is characterized by progressive impairments in pancreatic beta cell function, ${ }^{1-4}$ with an estimated decrease of about $25 \%$ over 5 years. ${ }^{2}$ The deterioration in glycemic control itself also aggravates pancreatic beta cell function, so-called glucotoxicity, leading to a vicious cycle. ${ }^{5}$ As a consequence, the proportion of patients who achieve their glycated hemoglobin (HbAlc) target decreases with longer diabetes http 
duration, despite increases in the number of prescribed antihyperglycemic agents. ${ }^{6-8}$ However, once hyperglycemia is appropriately corrected, it may be possible to eliminate glucotoxicity and ameliorate pancreatic beta cell function. ${ }^{9,10}$ Therefore, it is important to preserve beta cell function using appropriate antihyperglycemic agents.

Metformin, dipeptidyl peptidase-4 (DPP-4) inhibitors, and sulfonylureas (especially glimepiride) are commonly used in clinical practice. ${ }^{11-13}$ If patients taking these three agents require further treatment intensification, increasing the sulfonylurea dose is an option. However, sulfonylureas are associated with increased risk of hypoglycemia, ${ }^{14,15}$ especially at high doses, ${ }^{16}$ necessitating continued vigilance for hypoglycemia. By comparison, sodium-glucose cotransporter-2 (SGLT2) inhibitors, with a different antihyperglycemic mechanism, have the potential to be combined with commonly used antihyperglycemic agents. ${ }^{17-21}$ Adding an SGLT2 inhibitor may be an effective alternative to adjusting the glimepiride dose in such patients.

Some studies have suggested that SGLT2 inhibitors may confer improvements in beta cell function. ${ }^{22}$ It is desirable that beta cell function is evaluated as insulin secretion adjusted for whole-body insulin sensitivity, because insulin secretion has a hyperbolic relationship with whole-body insulin sensitivity. ${ }^{23}$ The disposition index (DI), the product of the insulin response to glucose and insulin sensitivity indices, has emerged as a valuable tool for the purpose of evaluating beta cell function. ${ }^{24}$ In fact, a short-term pilot study recently demonstrated that administration of an SGLT2 inhibitor improved beta cell function measured as DI. ${ }^{25}$

Currently, however, it is unknown whether adjusting the sulfonylurea dose or adding an SGLT2 inhibitor is more beneficial in terms of preserving beta cell function and glycemic control in patients with type 2 diabetes on triple therapy. Therefore, we performed a randomized, open-label, parallelgroup trial to compare the effects of add-on canagliflozin with glimepiride dose adjustment and glimepiride dose adjustment on pancreatic beta cell function measured in terms of the DI, in patients with type 2 diabetes with inadequate glycemic control despite stable triple therapy (metformin, teneligliptin, and glimepiride) plus diet and exercise therapy. We also explored which factors are related to the improvement in DI.

\section{Methods}

\section{Ethics}

The study was conducted in compliance with the Declaration of Helsinki and the Clinical Trials Act (Act
No. 16 of April 14, 2017). The study was approved by the Institutional Review Board and was registered with the University Hospital Medical Information Network Clinical Trials Registry (UMIN-CTR, UMIN000030208) on March 28, 2018. However, due to the new Clinical Research Act enforced on April 1, 2018, in Japan, studies not completed by March 31, 2019, were required to be rereviewed by a Certified Review Board and re-registered on the Japan Registry of Clinical Trials (jRCT). Therefore, this study was re-reviewed by Osaka University Clinical Research Review Committee, and re-registered with the jRCT on January 29, 2019 (jRCTs051180036).

\section{Patients}

Patients aged 20-74 years who provided informed consent and who had not achieved their individual glycemic target according to Japanese guidelines ${ }^{26}$ despite unchanged diet and exercise therapy over 12 weeks and stable doses of metformin (0-2250 mg/day), teneligliptin (20 mg/day), and glimepiride (0.5-2 mg/day) over 12 weeks were eligible for the study.

Patients with any of the following were excluded: type 1 diabetes mellitus, need for insulin therapy, history of hypersensitivity to canagliflozin, history of heart failure (New York Heart Association class IV), estimated glomerular filtration rate $<45 \mathrm{~mL} / \mathrm{min} / 1.73 \mathrm{~m}^{2}$, severe hepatic dysfunction, pregnancy, nursing or planning to become pregnant during the study, suspected or diagnosed malignant tumors, participating in another interventional study, and considered by the investigator to be inappropriate for the study for any other reason.

Concomitant use of the following drugs was prohibited from 12 weeks before the study to the end of the study: insulin, sulfonylureas other than glimepiride, glinides, biguanides other than metformin, DPP-4 inhibitors other than teneligliptin, GLP-1 receptor agonists, SGLT2 inhibitors except for canagliflozin during the treatment period and newly launched antidiabetic drugs or investigational products. Patients could use $\alpha$-glucosidase inhibitors or thiazolidinediones provided that they were started more than 12 weeks before the run-in period and was planned to continue administration at the same dose until the end of the study.

\section{Study Design}

This study was performed at Shiraiwa Medical Clinic (Osaka, Japan). It comprised a 2-4 week run-in period, a 24-week treatment period, and a 1-week wash-out period. 
At the start of the run-in period, the participants underwent a $75 \mathrm{~g}$ oral glucose tolerance test (OGTT). After the run-in period, they were randomized 1:1 to the glimepiride group (glimepiride dose adjustment) or the canagliflozin group (add-on canagliflozin $100 \mathrm{mg}$ and glimepiride dose adjustment) using a dynamic allocation method stratified by the OGTT-derived DI and the glimepiride dose at the start of the run-in period. Randomization was performed by central registration with an online registration system. In both groups, teneligliptin and metformin were continued at the same doses. Patients visited the clinic every 4 weeks. Twenty-four-hour blood glucose levels in daily life were monitored for 2 weeks after each visit by continuous glucose monitoring (CGM; FreeStyle Libre Pro; Abbott). The glimepiride dose was adjusted according to the prescribed algorithm based on the CGM data (Table S1) at the next visit. At the end of the treatment period, the patients returned to the regimen they had used in the run-in period for 1 week (wash-out period). The patients underwent a 75 g OGTT at the end of the wash-out period.

Prior to the OGTTs, the patients fasted for more than $10 \mathrm{~h}$ and were asked to refrain from taking the study drugs, concomitant medications, or restricted medications ( $\alpha$-glucosidase inhibitors, thiazolidines). Patients drank Trelan-G solution (=75 g of glucose) within $5 \mathrm{~min}$, and blood samples were obtained at $0 \mathrm{~min}, 30 \mathrm{~min}( \pm 5 \mathrm{~min}), 60$ $\min ( \pm 10 \mathrm{~min})$, and $120 \mathrm{~min}( \pm 10 \mathrm{~min})$.

The primary endpoint of this study was the change in DI from baseline to week 25. DI was calculated as $\left(\right.$ IAUC $_{\text {Ins0-120 }} /$ IAUC $\left._{\text {Glu0-120 }}\right) \times$ (Matsuda index), where IAUC $_{\text {Ins0-120 }}$ and $\mathrm{IAUC}_{\text {glu0-120 }}$ are the incremental areas under the insulin and glucose curves, respectively, from 0 to 120 min..$^{10,24,25,27}$ As the insulin secretion index and Matsuda index (index of insulin resistance) tend to be influenced by SGLT2 inhibitors, ${ }^{25}$ wash-out of the SGLT2 inhibitor is needed to evaluate the change in beta cell function after treatment. The effect of canagliflozin $(100 \mathrm{mg}$ ) on urinary glucose excretion is mostly abolished by 3 days after stopping administration. ${ }^{28}$ Therefore, we assessed the post-treatment DI after a 1-week wash-out to exclude the influence of canagliflozin on the calculation of DI from an OGTT. Secondary endpoints were changes in HbA1c, fasting plasma glucose (FPG), body weight, glycemic parameters derived from CGM, and glimepiride doses. Glycemic parameters derived from CGM data were the mean glucose, glucose standard deviation (SD), mean amplitude of glucose excursions (MAGE), total area for the range of glucose variability, and the proportion of time spent with glucose in hypoglycemic $(\leq 70 \mathrm{mg} / \mathrm{dL}$, $\leq 3.89 \mathrm{mmol} / \mathrm{L} ;<54 \mathrm{mg} / \mathrm{dL},<3.00 \mathrm{mmol} / \mathrm{L})$, normoglyce$\operatorname{mic}(>70$ to $<180 \mathrm{mg} / \mathrm{dL},>3.89$ to $<9.99 \mathrm{mmol} / \mathrm{L})$, and hyperglycemic $(\geq 180 \mathrm{mg} / \mathrm{dL}, \geq 9.99 \mathrm{mmol} / \mathrm{L})$ ranges. Safety evaluations include assessments of adverse events (AEs) described using the Medical Dictionary for Regulatory Activities/Japanese version 21.0 and laboratory variables. Hypoglycemia was defined as a blood glucose level of $\leq 70 \mathrm{mg} / \mathrm{dL}(\leq 3.89 \mathrm{mmol} / \mathrm{L})$ measured using an inhospital blood sample, a CGM level of $\leq 70 \mathrm{mg} / \mathrm{dL}$ $(\leq 3.89 \mathrm{mmol} / \mathrm{L})$, or the presence of symptoms of hypoglycemia.

\section{Determination of Sample Size}

For the change in DI from baseline to the week 25, we estimated a mean difference in the $\log (\mathrm{DI})$ of 0.48 (i.e. 1.62-fold of intergroup ratio; difference ratio 62\%) with an SD of 0.49 in the canagliflozin add-on group versus the glimepiride group based on an unpublished sub-group analysis using data for patients with an HbA1c of $7.0-8.0 \%$ (53.01-63.94 mmol/mol) in the TA-7284-05 study. ${ }^{17,29} \mathrm{We}$ estimated that a sample size of 17 patients per group was needed to achieve a power of $80 \%$. Taking into consideration the number of withdrawals, the target sample size was set at 40 patients (20 patients/group).

\section{Statistical Analyses}

Efficacy was analyzed using the full analysis set, which included all patients in whom DI was calculated in both the run-in and wash-out periods. Safety was assessed using the safety analysis set, which included all randomized patients, excluding any patients who did not receive any dose of canagliflozin or glimepiride.

Data are presented as the least squares mean (LS mean) with $95 \%$ CIs, geometric mean with $95 \%$ CI, or mean with SD. Because DI was expected to show a right-skewed distribution, the values were log-transformed prior to data analysis. Some secondary variables demonstrating a right-skewed distribution were also log-transformed. Comparisons between the canagliflozin and glimepiride groups for the change from baseline were made using ANCOVA with the baseline level as the covariate. Anti$\log$ transformation (exponential transformation) was performed to calculate the post/pre-dose ratios and the intergroup ratios (canagliflozin group/glimepiride group) with 95\% CIs. The post/pre-percent change (\%) or intergroup difference $(\%)$ was calculated as one subtracted from these 
values and multiplied by 100 . Similar analyses were made for the DI-related items.

For intergroup comparisons of $\mathrm{HbAlc}, \mathrm{FPG}$, and body weight, the change at the last time point (last observation carried forward, LOCF) was analyzed with the baseline level as a covariate, and the LS mean changes with $95 \%$ CIs are shown. For the glimepiride dose and CGM-derived parameters (mean, SD, MAGE, and total area for the range of glucose variability), the LS mean changes from baseline with $95 \%$ CIs are shown. For the changes at 24 weeks after administration or at 1 week after the treatment period, ANCOVA was performed using the baseline level as the covariate. Similarly, the changes at each time point were also analyzed as the reference. The mean and SD for the time course of the proportion of time in hypoglycemic $(\leq 70 \mathrm{mg} / \mathrm{dL}, \leq 3.89 \mathrm{mmol} / \mathrm{L} ;<54 \mathrm{mg} / \mathrm{dL}$, $<3.00 \mathrm{mmol} / \mathrm{L}$ ), normoglycemic ( $>70$ to $<180 \mathrm{mg} / \mathrm{dL},>3.89$ to $<9.99 \mathrm{mmol} / \mathrm{L})$, and hyperglycemic $(\geq 180 \mathrm{mg} / \mathrm{dL}$, $\geq 9.99 \mathrm{mmol} / \mathrm{L}$ ) ranges were determined from CGM data. The correlations between $\log (\mathrm{DI})$ and secondary endpoints using Pearson's correlation coefficient were determined in the canagliflozin group, glimepiride group, and in the overall cohort. The proportions of time in hypoglycemic, normoglycemic, and hyperglycemic ranges on CGM, and the correlations between $\log (\mathrm{DI})$ and secondary endpoints in the overall cohort were assessed in post hoc analyses.

All statistical analyses were performed using SAS version 9.4 (SAS Institute, Cary, NC, USA). Data management and statistical analyses were conducted by EP-CRSU Co., Ltd. (Tokyo, Japan).

\section{Results}

\section{Patients}

Between April 24 and August 29, 2018, a total of 40 patients were recruited, enrolled, and randomized to the two groups, with 20 patients per group (Figure S1). Thirty-nine patients completed the treatment period. One patient allocated to the canagliflozin group was withdrawn because this patient was found to meet an exclusion criterion (diagnosis of a malignant tumor or suspected malignant tumor) following randomization. Therefore, the canagliflozin group comprised 19 patients for efficacy analyses and 20 patients for safety analyses. Both groups were well balanced in terms of baseline characteristics (Table 1).

\section{Beta Cell Function and Glycemic Control}

The mean daily glimepiride dose decreased steadily in both groups, from about $0.8 \mathrm{mg}$ per day at baseline to
Table I Patient Characteristics (Full Analysis Set)

\begin{tabular}{|c|c|c|}
\hline & Canagliflozin & Glimepiride \\
\hline $\begin{array}{l}\mathrm{N} \\
\text { Males, } \mathrm{n}(\%) \\
\text { Females, } \mathrm{n}(\%) \\
\text { Age, years } \\
\text { Duration of diabetes, years } \\
\text { Body weight, } \mathrm{kg} \\
\text { BMl, } \mathrm{kg} / \mathrm{m}^{2}\end{array}$ & $\begin{array}{l}19 \\
9(47.4) \\
10(52.6) \\
59.4(8.66) \\
10.95(7.08) \\
66.71(11.66) \\
26.05(3.90)\end{array}$ & $\begin{array}{l}20 \\
10(50.0) \\
10(50.0) \\
54.8(9.70) \\
11.48(8.33) \\
69.43(19.63) \\
26.13(5.03)\end{array}$ \\
\hline $\begin{array}{l}\text { Complications, n (\%) } \\
\text { Diabetic retinopathy } \\
\text { Diabetic nephropathy } \\
\text { Diabetic neuropathy } \\
\text { Hypertension } \\
\text { Dyslipidemia }\end{array}$ & $\begin{array}{l}3(15.8) \\
0(0.0) \\
8(42.1) \\
9(47.4) \\
15(78.9)\end{array}$ & $\begin{array}{l}3(15.0) \\
4(20.0) \\
10(50.0) \\
12(60.0) \\
15(75.0)\end{array}$ \\
\hline $\begin{array}{l}\mathrm{HbAlc}, \% \\
\mathrm{mmol} / \mathrm{mol}\end{array}$ & $\begin{array}{l}7.95(0.76) \\
63.39(8.31)\end{array}$ & $\begin{array}{l}7.60(0.52) \\
59.57(5.68)\end{array}$ \\
\hline $\begin{array}{c}\mathrm{FPG}, \mathrm{mg} / \mathrm{dL} \\
\mathrm{mmol} / \mathrm{L}\end{array}$ & $\begin{array}{l}150.3(28.1) \\
8.34(1.56)\end{array}$ & $\begin{array}{l}137.4(24.4) \\
7.63(1.35)\end{array}$ \\
\hline $\begin{array}{l}\text { Metformin dose, mg } \\
\text { Teneligliptin dose, mg } \\
\text { Glimepiride dose, mg }\end{array}$ & $\begin{array}{l}684.2(298.6) \\
20.0(0.0) \\
0.789(0.48 I)\end{array}$ & $\begin{array}{l}1087.5(580.8) \\
20.0(0.0) \\
0.800(0.470)\end{array}$ \\
\hline $\begin{array}{l}\text { Use of other antihyperglycemic } \\
\text { agents } \\
\alpha \text {-glucosidase inhibitors } \\
\text { n (\%) } \\
\text { Dose, mg } \\
\text { Thiazolidinediones } \\
\text { n (\%) }\end{array}$ & $\begin{array}{l}2(10.5) \\
0.600 * \\
0(0.0)\end{array}$ & $\begin{array}{l}5(25.0) \\
0.575(0.183)\end{array}$ \\
\hline
\end{tabular}

Notes: Data are number (percent) of patients or mean (SD). *SD was not calculated because two patients used $\alpha$-glucosidase inhibitors in the canagliflozin group.

Abbreviations: SD, standard deviation; BMI, body mass index; HbAlc, glycated hemoglobin; FPG, fasting plasma glucose.

$0.069 \mathrm{mg}$ in the canagliflozin group and $0.188 \mathrm{mg}$ in the glimepiride group (Figure 1A). Overall, 15/19 and 12/20 patients in the canagliflozin and glimepiride groups, respectively, stopped glimepiride use during the treatment period. The between-group difference of glimepiride dose in the LS mean at week 24 was $-0.119 \mathrm{mg}(95 \% \mathrm{CI}$ -0.286 to $0.048, P=0.158$ ).

As shown in Figure 1B, HbA1c decreased from baseline to week 24 in the canagliflozin group but increased in the glimepiride group, with a significant difference in LS mean of $-0.72 \%$ at the LOCF $(95 \%$ CI $-1.20 \%$ to $-0.24 \%$, $P=0.005)(-7.9[-13.1$ to -2.6$] \mathrm{mmol} / \mathrm{mol})$. A significant reduction in FPG was observed in the canagliflozin group, with a difference in LS mean of $-27.0 \mathrm{mg} / \mathrm{dL}$ at the LOCF 
A $\quad \rightarrow$ Canagliflozin $(n=19)^{+} \rightarrow$ Glimepiride $(n=20)$

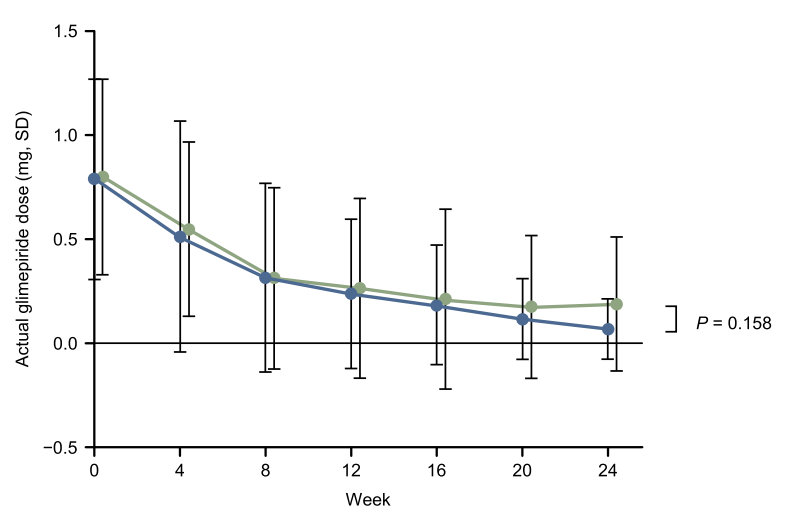

C

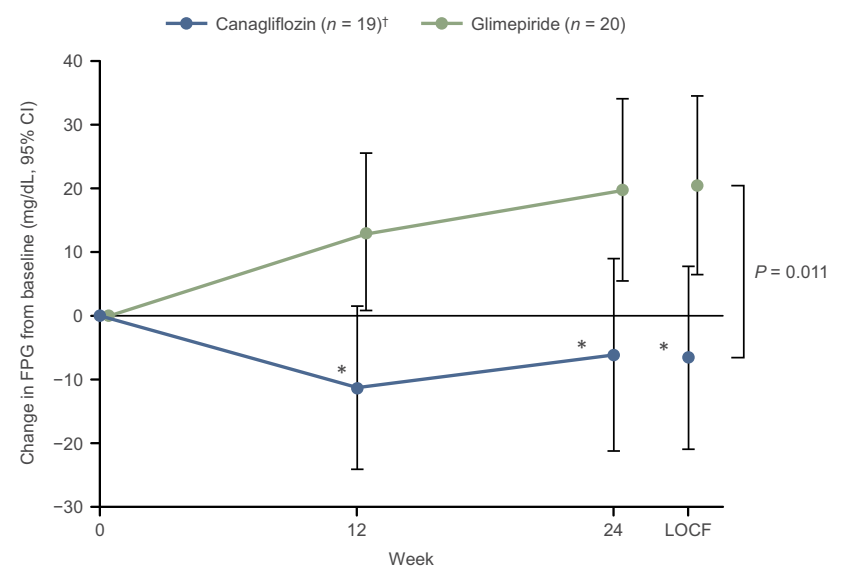

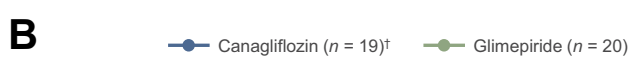
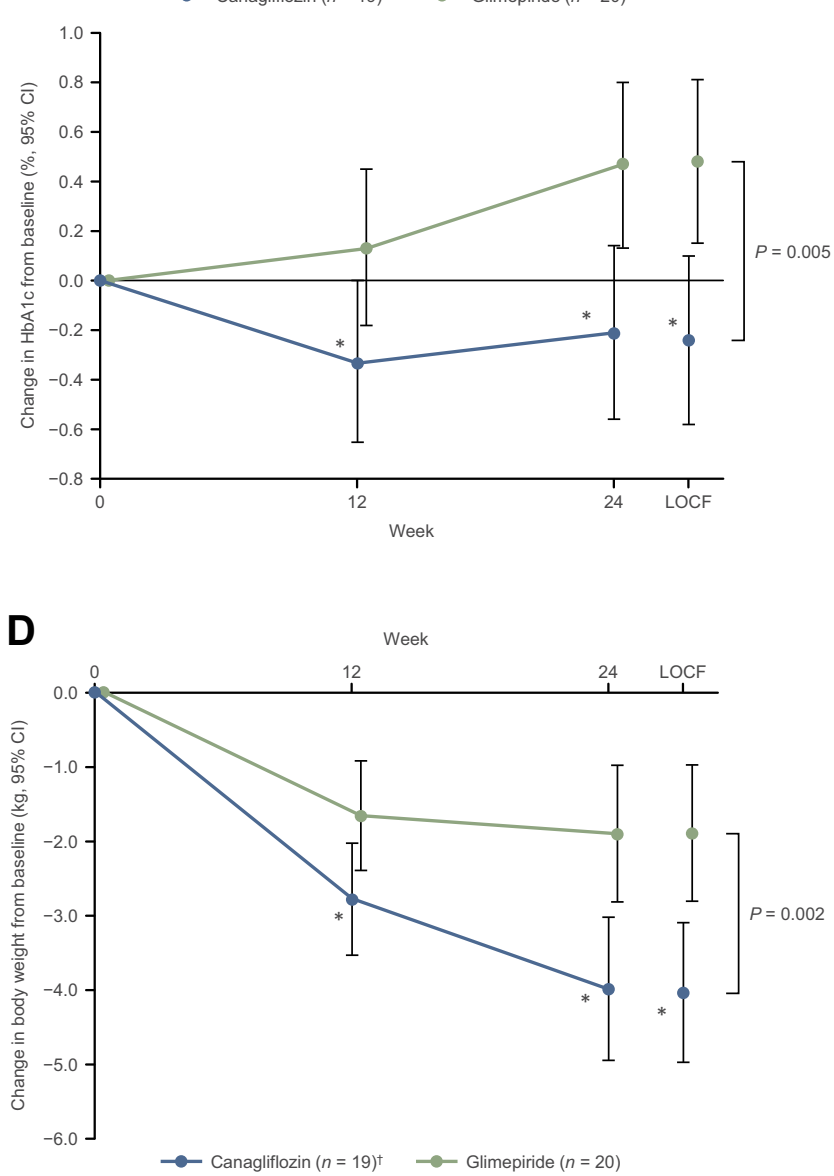

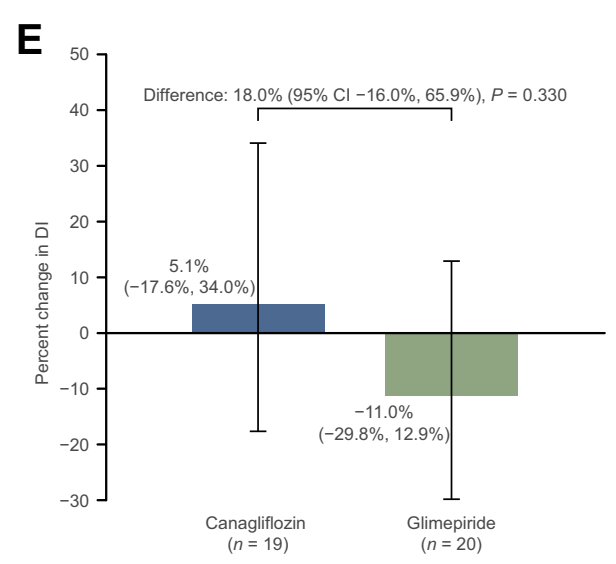

Figure I Glimepiride doses over the preceding 4 weeks (A) and changes in HbAlc (B), FPG (C), body weight (D), and percent change in DI (E) from baseline. Notes: Values are presented as the mean \pm SD $(\mathbf{A})$, LS mean $\pm 95 \% \mathrm{Cl}(\mathbf{B}-\mathbf{D})$, or intergroup ratio with $95 \% \mathrm{Cl}(\mathbf{E})$. $* \mathrm{P}<0.05$ vs the glimepiride group $(\mathrm{ANCOVA})$. Canagliflozin group $n=19$, glimepiride group $n=20$, unless otherwise indicated. ${ }^{\dagger} n=18$ at week 24 . HbAl c: IFCC value $(\mathrm{mmol} / \mathrm{mol})=10.93 \times \mathrm{NGSP}$ value $(\%)-23.5$. Glucose: I mg/dL $=0.0555 \mathrm{mmol} / \mathrm{L}$.

Abbreviations: $\mathrm{Cl}$, confidence interval; DI, disposition index; FPG, fasting plasma glucose; HbA Ic, glycated hemoglobin; IFCC, International Federation of Clinical Chemistry and Laboratory Medicine; LOCF, last observation carried forward; LS, least squares; NGSP, National Glycohemoglobin Standardization Program; SD, standard deviation.

$(95 \% \mathrm{CI}-47.3$ to $-6.6 \mathrm{mg} / \mathrm{dL}, P=0.011)(-1.50[-2.63$ to $-0.37] \mathrm{mmol} / \mathrm{L}$ ) (Figure 1C). Although body weight decreased in both groups, the magnitude of the decrease at LOCF was greater in the canagliflozin group (LS mean: -4.03 vs -1.88

$\mathrm{kg}$; difference in LS mean: $-2.15 \mathrm{~kg}, 95 \% \mathrm{CI}-3.46$ to -0.84 $\mathrm{kg}, P=0.002$; Figure 1D). 
The primary endpoint, the change in DI from baseline to week 25, is shown in Figure 1E and Table S2. DI increased by $5.1 \%$ in the canagliflozin group and decreased by $11.0 \%$ in the glimepiride group. Although the ratio for the change in DI was $18.0 \%$ greater in the canagliflozin group, this difference was not statistically significant $(95 \% \mathrm{CI}-16.0 \%$ to $65.9 \%, P=0.330$ ).

As DI is calculated from OGTT-associated indices (Matsuda index, $\mathrm{IAUC}_{\mathrm{Ins} 0-120}$ and $\mathrm{IAUC}_{\mathrm{Glu0-120}}$ ), we examined the changes in the indices differently. However, we found no significant differences in the changes in these indices between the two groups (Table S2).

We also examined the changes in glycemic parameters derived from CGM (Figure 2). As illustrated in Figure 2A-D, the measures of mean glucose and mean glucose variability (SD, MAGE, and total area for the range of glucose variability) showed tendencies to decrease in the canagliflozin
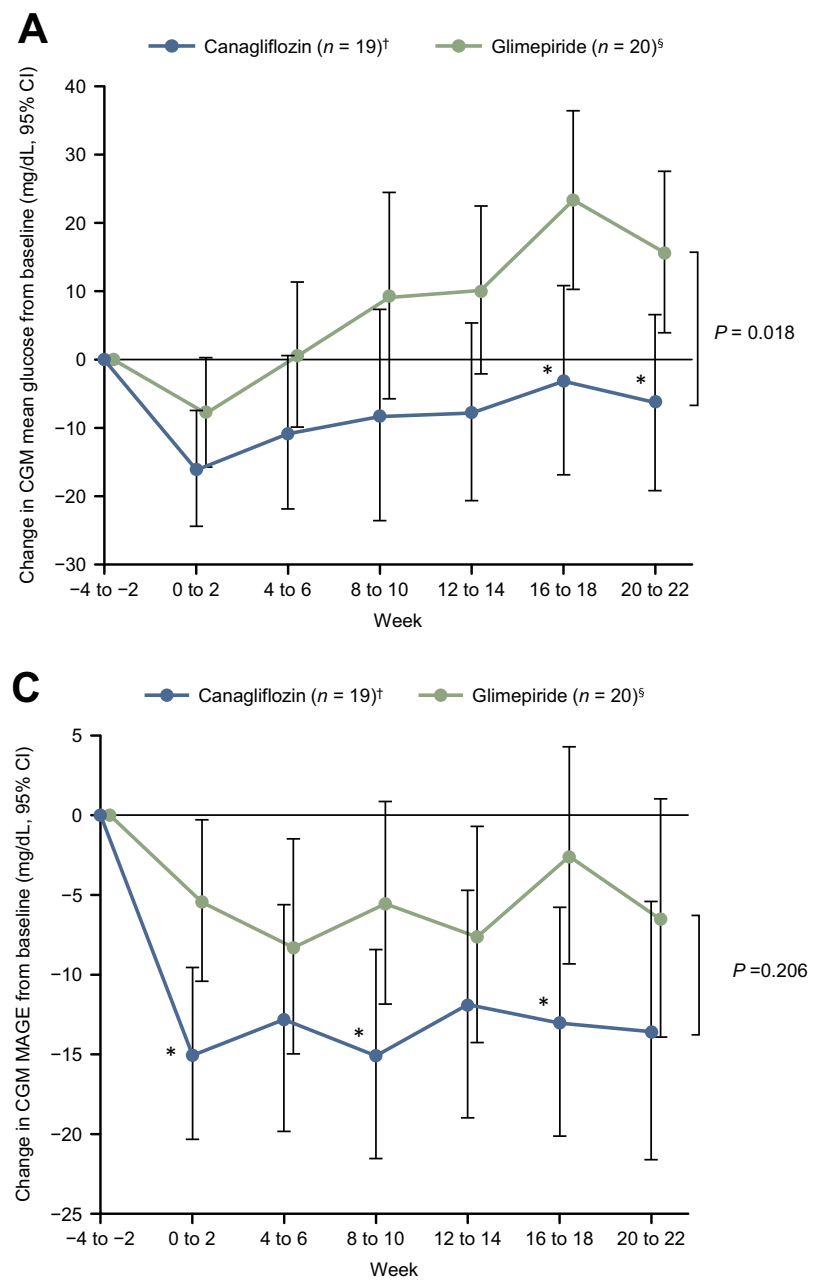

group within 4-8 weeks after baseline and remained at lower levels compared with the glimepiride group. We observed trends toward increased time spent in the normoglycemic range and decreased time spent in the hyperglycemic range in the canagliflozin group, whereas the time spent in the hypoglycemic range decreased in both groups (Figure 2E-H). The proportion of time with nocturnal hypoglycemia (0:00-5:59) decreased in both groups (Figure S2).

We next determined the correlations between change in $\log (\mathrm{DI})$ and efficacy endpoints in the overall cohort $(n=39)$ and in both treatment groups separately (Figure 3). In the overall cohort, the change in $\log (\mathrm{DI})$ was significantly correlated with the changes in HbAlc $(r=-0.448, P=0.004)$, FPG $(r=-0.486, P=0.002)$, mean glucose $(r=-0.588$, $P<0.001)$, MAGE $(r=-0.477, P=0.003)$ and the proportions of time spent in the hyperglycemic $(r=-0.638, P<$ $0.001)$ and normoglycemic $(r=0.647, P<0.001)$ ranges.
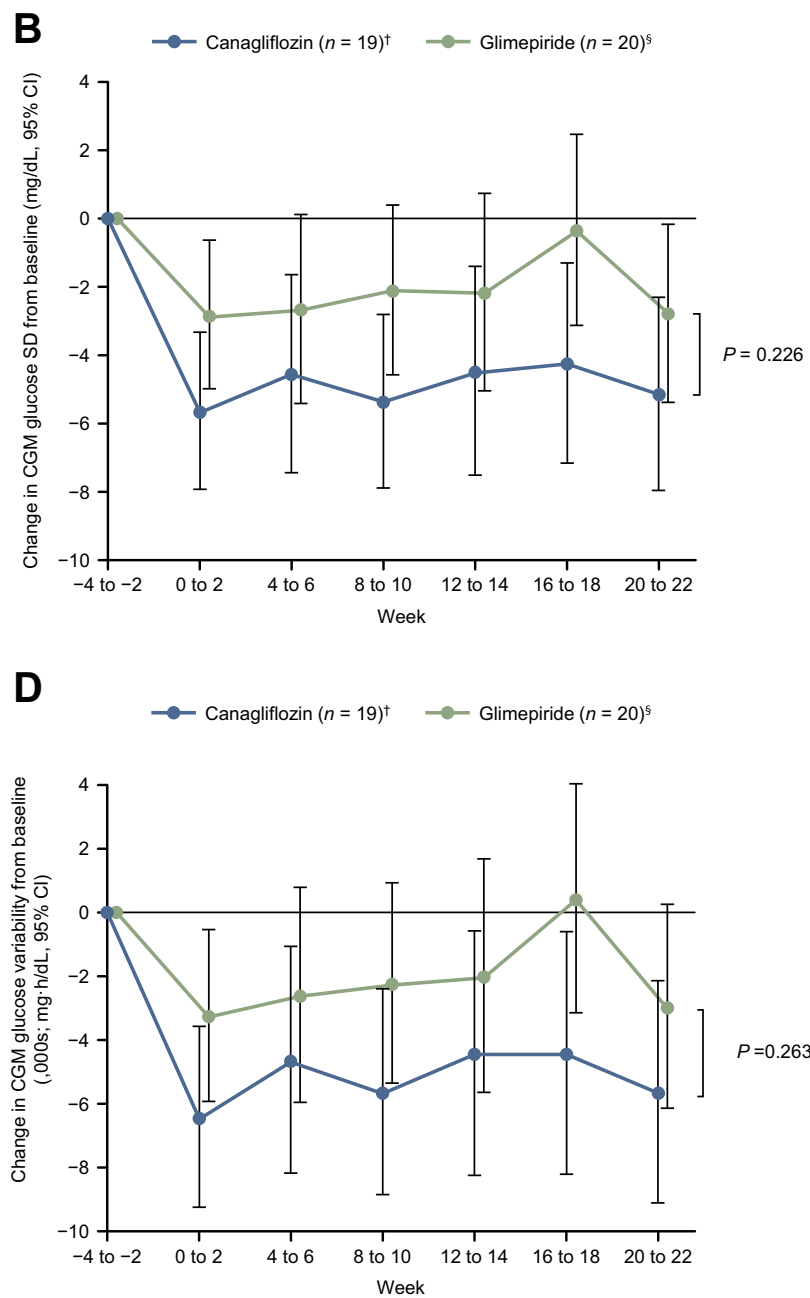

Figure 2 Continued. 

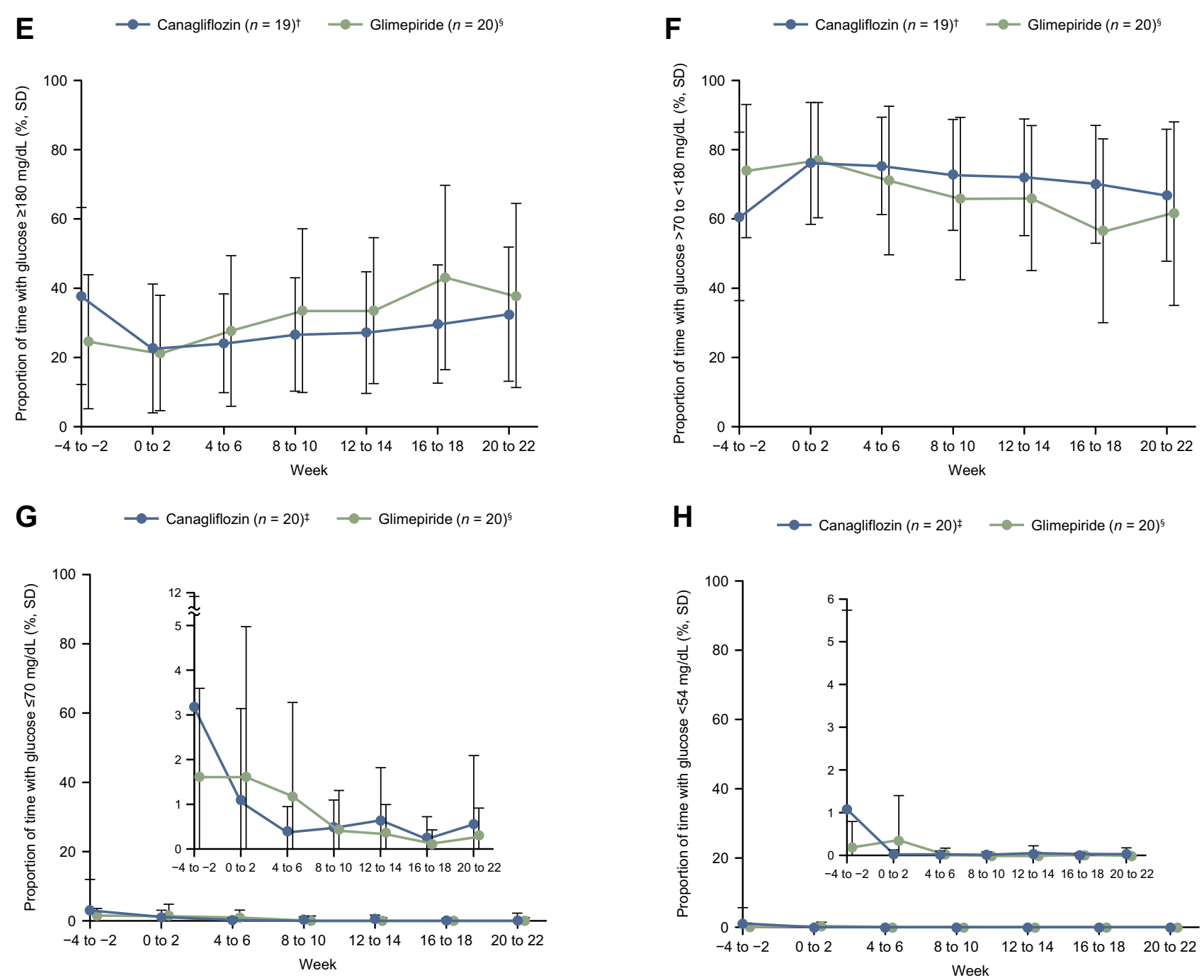

Figure 2 (A-D) Changes in mean glucose (A), glucose SD (B), MAGE (C), and total area for the range of glucose variability (D) determined by CGM. (E-H) The proportion of time with glucose levels in hyperglycemic $(\geq 180 \mathrm{mg} / \mathrm{dL}$, $\geq 9.9 \mathrm{mmol} / \mathrm{L}$, E), normoglycemic $(>70$ to $<180 \mathrm{mg} / \mathrm{dL},>3.89 \mathrm{mmol} / \mathrm{L}$ to $<9.99 \mathrm{mmol} / \mathrm{L}$, F), and hypoglycemic ( $\leq 70 \mathrm{mg} / \mathrm{dL}, \leq 3.89 \mathrm{mmol} / \mathrm{L}, \mathbf{G} ;<54 \mathrm{mg} / \mathrm{dL}$, $<3.00 \mathrm{mmol} / \mathrm{L}, \mathbf{H}$ ) ranges, as determined by CGM.

Notes: The insets in ( $\mathbf{G}$ and $\mathbf{H})$ show a magnified axis for the proportion of time. CGM was performed over 2 weeks before each 4 weekly visit. Values are presented as the LS mean \pm $95 \% \mathrm{Cl}(\mathbf{A}-\mathbf{D})$ or mean $\pm \mathrm{SD}(\mathbf{E}-\mathbf{H})$. ${ }^{*} P<0.05$ vs the glimepiride group (ANCOVA). Statistical comparisons of the two groups were not performed in $(\mathbf{E}-\mathbf{H})$. Canagliflozin group $n=19$ $(\mathbf{A}-\mathbf{F})$ or $n=20(\mathbf{G}$ and $\mathbf{H})$, glimepiride group $n=20$, unless otherwise indicated. ${ }^{\dagger} n=18$ at baseline, $n=17$ at week $24 ;{ }^{\ddagger} n=18$ at Week $24 ;{ }^{\S} n=19$ at week 12 . Glucose: I mg/dL $=$ $0.0555 \mathrm{mmol} / \mathrm{L}$.

Abbreviations: CGM, continuous glucose monitoring; Cl, confidence interval; LS, least squares; MAGE, mean amplitude of glucose excursions; SD, standard deviation.

These correlations were observed in the canagliflozin and glimepiride groups individually, except for the change in FPG in the canagliflozin group and the changes in HbAlc and MAGE in the glimepiride group. The change in $\log (\mathrm{DI})$ was not correlated with the change in body weight in the overall cohort or in either group (Figure 3C).

\section{Safety}

Safety was assessed in terms of vital signs, laboratory data, and AEs. The changes in laboratory values are shown in Table S3. AEs occurred in $20(100 \%)$ and 18
(90\%) patients in the canagliflozin and glimepiride groups, respectively, and included serious AEs in one patient in each group (hepatic neoplasm in the canagliflozin group and hydronephrosis in the glimepiride group) and adverse drug reactions in 15 patients in each group (Table S4). Hypoglycemia was the most frequent AE, with 44 episodes occurring in 12 patients $(60 \%)$ in the canagliflozin group and 79 episodes in 14 patients $(70 \%)$ in the glimepiride group. Only three episodes of hypoglycemia with symptoms were reported in the canagliflozin group and were not severe; all other episodes were detected by CGM, 
in other words, unconscious hypoglycemia. The AEs blood ketone body increased, and pruritus genital were observed in six and three patients in the canagliflozin group, respectively; all of these events were not severe.

\section{Discussion}

In this study, patients with type 2 diabetes on triple combination therapy were randomized to undergo either glimepiride dose adjustment or glimepiride dose adjustment and the addition of canagliflozin to ongoing treatment. During the 24-week treatment period, the mean glimepiride dose was decreased in both groups due to low glucose levels detected by CGM in accordance with the prespecified algorithm. The change in DI was $-11 \%$ in the glimepiride group and $5 \%$ in the canagliflozin group, with an intergroup difference ratio of $18 \%$, although this was not statistically significant. HbA1c and FPG levels were significantly lower in the canagliflozin
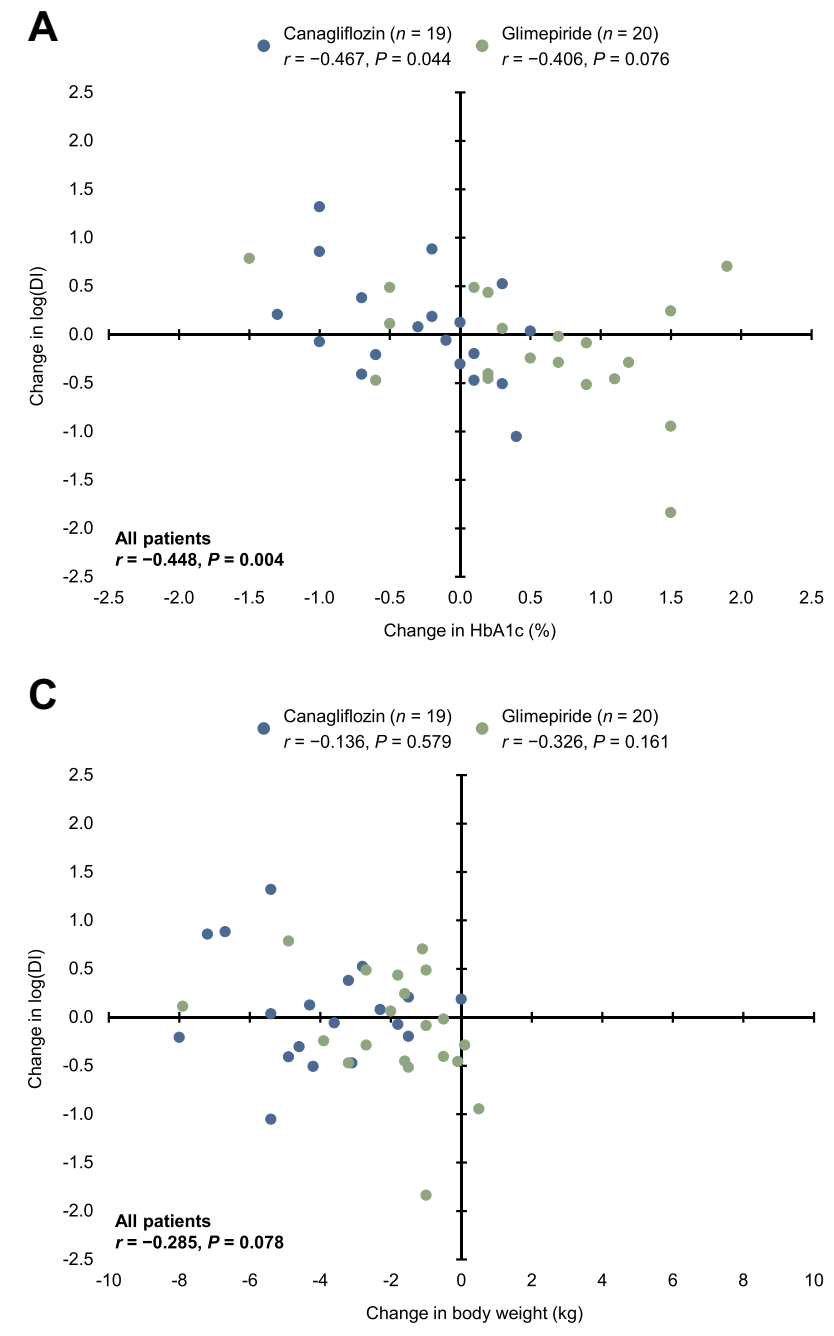

Figure 3 Continued. group than in the glimepiride group. The CGM data, including the mean, SD and proportion of time with glucose levels in hyperglycemic, normoglycemic and hypoglycemic ranges, suggest that canagliflozin improved the daily blood glucose profile. A total of 44 and 79 hypoglycemic episodes were observed in the canagliflozin group and the glimepiride group, respectively. In addition, we found that the change in DI was correlated with improvements in glycemic control in terms of glucose levels and variability.

The TA-7284-05 study ${ }^{17,29}$ was used as a reference to determine the sample size for the present study. The change in DI in the present study was not statistically significant, indicating that DI was not improved by treatment with canagliflozin in the current population to the extent expected from the TA-7284-05 study (i.e. an improvement by $62 \%$ ). However, the patients enrolled in the present study had a longer duration of diabetes, of about 10 years, and were on
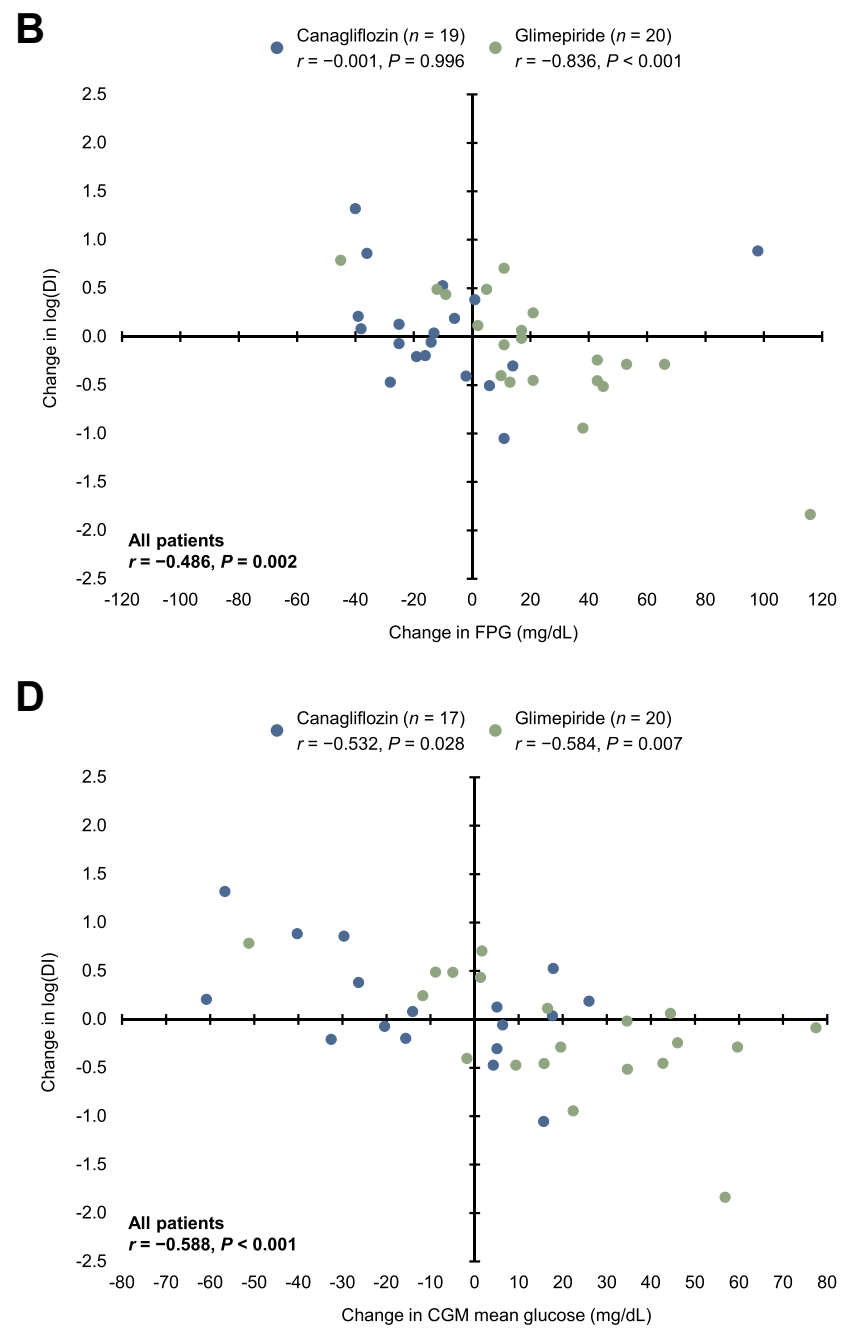

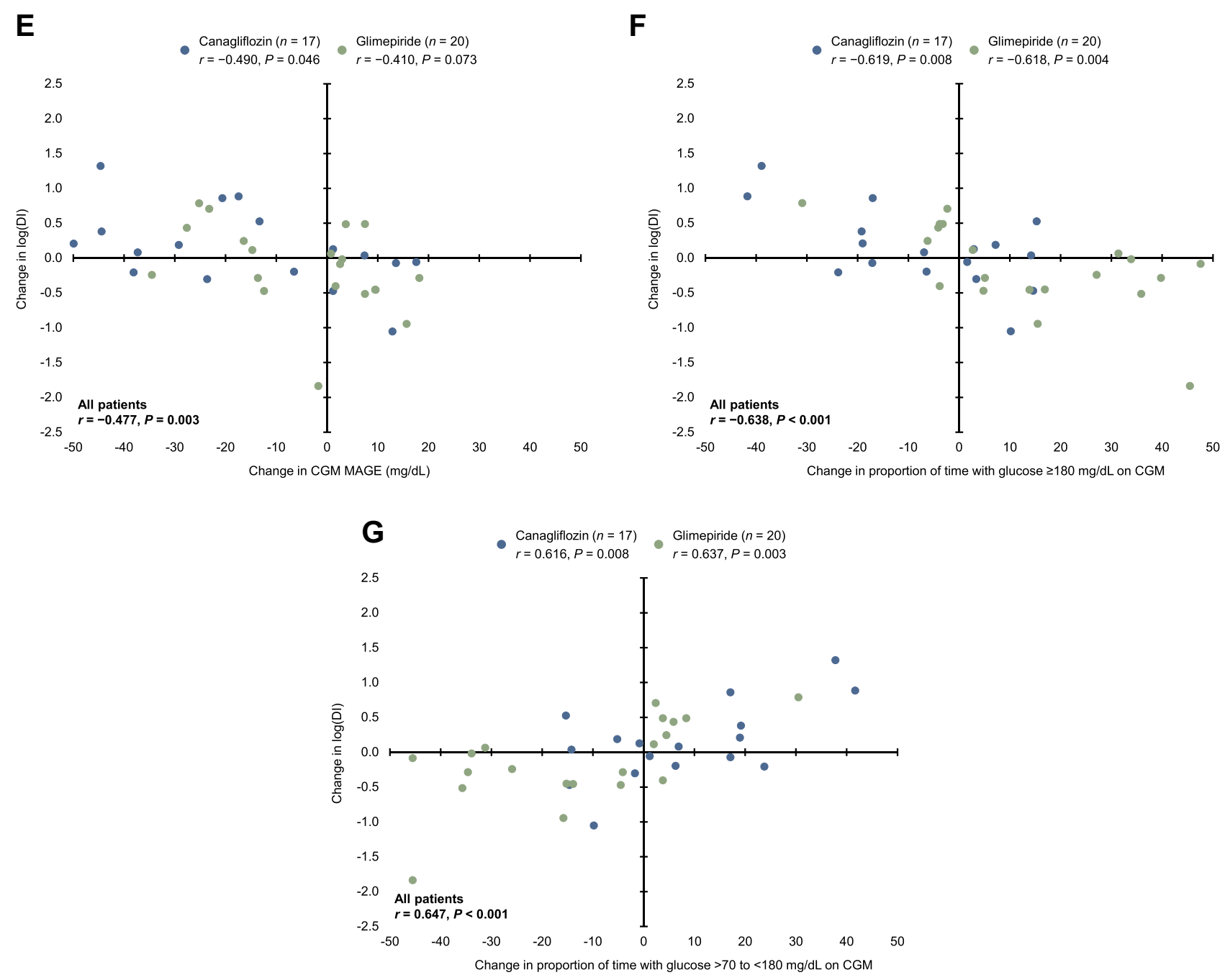

Figure 3 Correlations between the changes in $\log (\mathrm{DI})$ and the changes in HbAlc (A), FPG (B), body weight (C), mean glucose (D), MAGE (E), and proportions of time with glucose level in hyperglycemic ( $\geq 180 \mathrm{mg} / \mathrm{dL}, \geq 9.99 \mathrm{mmol} / \mathrm{L}, \mathbf{F})$ and normoglycemic $(>70$ to $<180 \mathrm{mg} / \mathrm{dL},>3.89$ to $<9.99 \mathrm{mmol} / \mathrm{L}, \mathbf{G}) \mathrm{ranges}$.

Note: $\mathrm{HbAlc}$ IFCC value $(\mathrm{mmol} / \mathrm{mol})=10.93 \times \mathrm{NGSP}$ value $(\%)-23.5$. Glucose: $\mathrm{I} \mathrm{mg} / \mathrm{dL}=0.0555 \mathrm{mmol} / \mathrm{L}$.

Abbreviations: DI, disposition index; FPG, fasting plasma glucose; HbAlc, glycated hemoglobin; IFCC, International Federation of Clinical Chemistry and Laboratory Medicine; NGSP, National Glycohemoglobin Standardization Program.

the triple therapy (metformin, teneligliptin, and glimepiride) at baseline, in contrast to the TA-7284-05 study (duration of diabetes: about 5 years; diet/exercise therapy only). Therefore, it may have been difficult to achieve the level of improvement in DI seen in the TA-7284-05 study in the present study.

We previously reported that medical nutrition therapy without pharmacotherapy aided the recovery of DI in patients with newly diagnosed type 2 diabetes presenting with extreme hyperglycemia and also show the correlation between DI and HbA1c. ${ }^{10}$ Consistently, we found a correlation between the improvements in DI and glucose control in a population of patients with more advanced diabetes. A number of cross-sectional studies and an interventional study have documented an association between beta cell function and glycemic variability. ${ }^{30-32}$ However, in those studies, glycemic variability was evaluated by self-monitored blood glucose $\mathrm{e}^{30,31}$ or CGM under controlled meal conditions. ${ }^{32}$ Unlike these earlier studies, glycemic levels and variability were assessed by CGM in real daily-life conditions over 2 -week periods in the present study. The results of our interventional study provide further, novel evidence for the association between mean blood glucose or glycemic variability and beta cell function in daily life. Our previous in vitro studies, which explored the underlying mechanisms in beta cell glucotoxicity, revealed that 
alleviating glucotoxicity and lipotoxicity is associated with improvements in islet gene expression of Pdx1, Mafa, and Slc2a2, key factors involved in beta cell function. ${ }^{33,34}$ Thus, it is possible that reducing glucotoxicity may contribute to the improvement in beta cell function and better glycemic control observed in the current study.

CGM in daily life in the current study revealed frequent asymptomatic hypoglycemia despite low doses of glimepiride in patients presenting with hyperglycemia and no obvious signs of hypoglycemia at baseline. Accordingly, and somewhat unexpectedly, it was necessary to lower the dose of glimepiride, not increase it, in many patients, even in the glimepiride group. Hypoglycemia is associated with increased cardiovascular risk, cognitive dysfunction, dementia, and vision disorders. ${ }^{35,36}$ In patients with recurrent hypoglycemia, the brain adapts to hypoglycemia such that subsequent symptoms manifest at lower plasma glucose concentrations, reducing awareness of hypoglycemia. ${ }^{36}$ Therefore, it is important to adjust the dose of glimepiride to avoid the risk of hypoglycemia. The current findings indicate that glimepiride is associated with increased risk of hypoglycemia, even when administered at low doses, in patients with inadequate glycemic control on the triple therapy and that canagliflozin may improve glycemic control without increasing the risk of hypoglycemia in these patients.

AEs other than hypoglycemia that were observed in the canagliflozin group only included blood ketone body increased and pruritus genital. These AEs have previously been documented in patients treated with SGLT2 inhibitors, including canagliflozin, in clinical practice. ${ }^{17-20,29,37}$ These AEs were mild in severity in this study. Our results demonstrate the tolerability of adding canagliflozin to ongoing triple combination therapy.

Limitations of this study include its small sample size, the short-term treatment period, and open-label design. The sample size was small and did not have sufficient power to detect a significant difference in DI in this population. The longer-term effects of canagliflozin await confirmation.

In conclusion, adding canagliflozin to the triple therapy improved beta cell function by $18 \%$, but it did not reach statistical significance. Treatment with canagliflozin was associated with improvements in overall glycemic control and glycemic variability, with a relatively lower risk of hypoglycemia compared with glimepiride dose adjustment. This study also revealed correlations between the improvement in beta cell function (change in DI) and changes in markers of glycemic control.

\section{Prior Publication}

Results of this study were presented as an abstract and poster at the International Diabetes Federation Congress 2019, December 2-6, Busan, South Korea.

\section{Data Sharing Statement}

The datasets generated and/or analyzed during the current study are available from the corresponding author on reasonable request.

\section{Acknowledgments}

The authors would like to thank Ms. A Yano (EP-CRSU Co., Ltd.) for coordinating the study and Ms. Y Yamamoto (EP-CRSU Co., Ltd.) for conducting the statistical analysis. The authors thank Nicholas D. Smith (EMC K.K.) for medical writing support, which was funded by Mitsubishi Tanabe Pharma Corporation.

\section{Author Contributions}

All authors made substantial contributions to conception and design, acquisition of data, or analysis and interpretation of data; took part in drafting the article or revising it critically for important intellectual content; agreed to submit to the current journal; gave final approval of the version to be published; and agree to be accountable for all aspects of the work. In terms of specific contributions, M Takahara and T Matsuoka made substantial contributions to the study concept, study design, and discussion of the results; $\mathrm{T}$ Shiraiwa made substantial contributions to the study concept, study design, data collection, and discussion of the results; K Yamamoto, Y Maeno, Y Shiraiwa, and Y Yoshida made substantial contributions to data collection; $\mathrm{N}$ Katakami and I Shimomura made substantial contributions to the discussion of the results; and H Iijima, H Katsumata, $\mathrm{K}$ Arakawa, and $\mathrm{T}$ Hashimoto made substantial contributions to study design and discussion of the results.

\section{Funding}

This study was funded by Mitsubishi Tanabe Pharma Corporation.

\section{Disclosure}

M Takahara has received grants and research support fees from The Japan Diabetes Society. He has also received endowed chair funded by AstraZeneca K.K., Keiseikai Medical Corporation, Mitsubishi Tanabe Pharma Corporation, MSD K.K., Nippon Boehringer Ingelheim Co., 
Ltd., Novo Nordisk Pharma Ltd., Ono Pharmaceutical Co., Ltd., and Taisho Toyama Pharmaceutical Co. Ltd. T Shiraiwa has received consulting fees and/or speakers' bureau from Sanofi K.K., and Takeda Pharmaceutical Co., Ltd. He has also received research support from AstraZeneca K.K., Mitsubishi Tanabe Pharma Corporation, Nippon Boehringer Ingelheim Co., Ltd., Novo Nordisk Pharma Ltd., Sanofi K.K., and Takeda Pharmaceutical Co., Ltd.

$\mathrm{T}$ Matsuoka has received research support from Daiichi Sankyo Co., Ltd., and Takahashi Industrial and Economia Research Foundation.

N Katakami has received consulting fees and/or speakers' bureau from MSD K.K., and Ono Pharmaceutical Co., Ltd. $\mathrm{He}$ has also received endowed chair funded by Kowa Company Ltd.

I Shimomura has received consulting fees and/or speakers' bureau from Astellas Pharma Inc., Eli Lilly Japan K.K., Kowa Company Ltd., Mitsubishi Tanabe Pharma Corporation, MSD K.K., Nippon Boehringer Ingelheim Co., Ltd., Novo Nordisk Pharma Ltd., Ono Pharmaceutical Co., Ltd., Sanofi K.K., Sanwa Kagaku Kenkyusho Co., Ltd., and Takeda Pharmaceutical Co., Ltd. He has also received research support from Japan Agency for Medical Research and Development, Kowa Company Ltd., and Rohto Pharmaceutical Co., Ltd. He also has received scholarship grants from Astellas Pharma Inc., AstraZeneca K.K., Daiichi Sankyo Co., Ltd., Japan Diabetes Foundation, Japan Foundation for Applied Enzymology, Kowa Company Ltd., Kowa Life Science Foundation, Kyowa Kirin Co., Ltd., Novartis Pharma K.K., Novo Nordisk Pharma Ltd., Midori Health Care Foundation, Mitsubishi Tanabe Pharma Corporation, MSD K.K., MSD Life Science Foundation, Ono Pharmaceutical Co., Ltd., Osaka Kaisei Hospital, Sanofi K.K., Sumitomo Dainippon Pharma Co., Ltd., Suzuken Memorial Foundation, Takeda Pharmaceutical Co., Ltd., TEIJIN PHARMA LIMITED, Terumo Corporation, and The Japan Diabetes Society.

H Iijima, H Katsumata, K Arakawa and T Hashimoto are employees of Mitsubishi Tanabe Pharma Corporation.

The aforementioned authors report no other potential conflicts of interest for this work.

K Yamamoto, Y Maeno, Y Shiraiwa and Y Yoshida have no conflicts of interest.

\section{References}

1. Skyler JS, Bakris GL, Bonifacio E, et al. Differentiation of diabetes by pathophysiology, natural history, and prognosis. Diabetes. 2017;66 (2):241-255. doi:10.2337/db16-0806
2. U.K. Prospective Diabetes Study group. U.K. prospective diabetes study 16. Overview of 6 years' therapy of type II diabetes: a progressive disease. U.K. Prospective Diabetes Study Group. Diabetes. 1995;44(11):1249-1258. doi:10.2337/diab.44.11.1249

3. Festa A, Williams K, D'Agostino R Jr, Wagenknecht LE, Haffner SM. The natural course of beta-cell function in nondiabetic and diabetic individuals: the insulin resistance atherosclerosis study. Diabetes. 2006;55(4):1114-1120. doi:10.2337/diabetes.55.04.06. $\mathrm{db} 05-1100$

4. Kahn SE, Haffner SM, Heise MA, et al. Glycemic durability of rosiglitazone, metformin, or glyburide monotherapy. $N$ Engl $J$ Med. 2006;355(23):2427-2443. doi:10.1056/NEJMoa066224

5. Leahy JL, Bonner-Weir S, Weir GC. Beta-cell dysfunction induced by chronic hyperglycemia. Current ideas on mechanism of impaired glucose-induced insulin secretion. Diabetes Care. 1992;15(3):442455. doi:10.2337/diacare.15.3.442

6. Yokoyama H, Oishi M, Takamura H, et al. Large-scale survey of rates of achieving targets for blood glucose, blood pressure, and lipids and prevalence of complications in type 2 diabetes (JDDM 40). BMJ Open Diabetes Res Care. 2016;4(1):e000294. doi:10.1136/ bmjdrc-2016-000294

7. Franch-Nadal J, Roura-Olmeda P, Benito-Badorrey B, RodriguezPoncelas A, Coll-de-Tuero G, Mata-Cases M. Metabolic control and cardiovascular risk factors in type 2 diabetes mellitus patients according to diabetes duration. Fam Pract. 2015;32(1):27-34. doi:10.1093/fampra/cmu048

8. Hayashino Y, Izumi K, Okamura S, Nishimura R, Origasa H, Tajima N. Duration of diabetes and types of diabetes therapy in Japanese patients with type 2 diabetes: the Japan diabetes complication and its prevention prospective study 3 (JDCP study 3). J Diabetes Investig. 2017;8(2):243-249. doi:10.1111/jdi.12550

9. Rossetti L, Shulman GI, Zawalich W, DeFronzo RA. Effect of chronic hyperglycemia on in vivo insulin secretion in partially pancreatectomized rats. J Clin Invest. 1987;80(4):1037-1044. doi:10.1172/JCI113157

10. Takahara M, Shiraiwa T, Katakami N, Matsuoka TA, Shimomura I. Marked recovery from glucotoxicity of beta-cell function after medical nutrition therapy without pharmacotherapy in type 2 diabetic outpatients with extreme hyperglycemia: a pilot retrospective study. Endocr J. 2017;64(11):1125-1129. doi:10.1507/endocrj.EJ17-0222

11. Lipska KJ, Yao X, Herrin J, et al. Trends in drug utilization, glycemic control, and rates of severe hypoglycemia, 2006-2013. Diabetes Care. 2017;40(4):468-475. doi:10.2337/dc16-0985

12. Montvida O, Shaw J, Atherton JJ, Stringer F, Paul SK. Long-term trends in antidiabetes drug usage in the U.S.: real-world evidence in patients newly diagnosed with type 2 diabetes. Diabetes Care. 2018;41(1):69-78. doi:10.2337/dc17-1414

13. Yamamoto-Honda R, Takahashi Y, Mori Y, et al. Changes in antidiabetic drug prescription and glycemic control trends in elderly patients with type 2 diabetes mellitus from 2005-2013: an analysis of the National Center Diabetes Database (NCDD-03). Intern Med. 2018;57(9):1229-1240. doi:10.2169/internalmedicine.9481-17

14. Deacon CF, Lebovitz HE. Comparative review of dipeptidyl peptidase-4 inhibitors and sulphonylureas. Diabetes Obes Metab. 2016;18 (4):333-347. doi:10.1111/dom.12610

15. Namba M, Iwakura T, Nishimura R, et al. The current status of treatment-related severe hypoglycemia in Japanese patients with diabetes mellitus: a report from the Committee on a Survey of Severe Hypoglycemia in the Japan Diabetes Society. J Diabetes Investig. 2018;9(3):642-656. doi:10.1111/jdi.12790

16. Ikeda Y, Kubo T, Oda E, Abe M, Tokita S. Incidence rate and patient characteristics of severe hypoglycemia in treated type 2 diabetes mellitus patients in Japan: retrospective diagnosis procedure combination database analysis. J Diabetes Investig. 2018;9 (4):925-936 
17. Inagaki N, Harashima SI, Iijima H. Canagliflozin for the treatment of type 2 diabetes: a comparison between Japanese and non-Japanese patients. Expert Opin Pharmacother. 2018;19(8):895-908. doi:10. 1080/14656566.2018.1473378

18. Yokote K, Terauchi Y, Nakamura I, Sugamori H. Real-world evidence for the safety of ipragliflozin in elderly Japanese patients with type 2 diabetes mellitus (STELLA-ELDER): final results of a postmarketing surveillance study. Expert Opin Pharmacother. 2016;17 (15):1995-2003. doi:10.1080/14656566.2016.1219341

19. Goda M, Yamakura T, Sasaki K, Tajima T, Ueno M. Safety and efficacy of canagliflozin in elderly patients with type 2 diabetes mellitus: a 1-year post-marketing surveillance in Japan. Curr Med Res Opin. 2018;34(2):319-327. doi:10.1080/03007995.2017.1392293

20. Nakamura I, Maegawa H, Tobe K, Uno S. Safety and effectiveness of ipragliflozin for type 2 diabetes in Japan: 12-month interim results of the STELLA-LONG TERM post-marketing surveillance study. Adv Ther. 2019;36(4):923-949. doi:10.1007/s12325-019-0895-1

21. Ito Y, Van Schyndle J, Nishimura T, Sugitani T, Kimura T. Drug utilization patterns in patients with diabetes initiating sodium glucose co-transporter-2 inhibitors (SGLT2i) in Japan: a multi-database study (2014-2017). Diabetes Ther. 2019;10(6):2233-2249. doi:10.1007/ s13300-019-00710-2

22. Kaneto H, Obata A, Kimura T, et al. Beneficial effects of sodiumglucose cotransporter 2 inhibitors for preservation of pancreatic betacell function and reduction of insulin resistance. J Diabetes. 2017;9 (3):219-225. doi:10.1111/1753-0407.12494

23. Kahn SE, Prigeon RI, McCullough DK, et al. Quantification of the relationship between insulin sensitivity and beta-cell function in human subjects: evidence for an hyperbolic function. Diabetes. 1993;42:1663-1667. doi:10.2337/diab.42.11.1663

24. Retnakaran R, Qi Y, Goran MI, Hamilton JK. Evaluation of proposed oral disposition index measures in relation to the actual disposition index. Diabet Med. 2009;26(12):1198-1203. doi:10.1111/j.14645491.2009.02841.x

25. Takahara M, Shiraiwa T, Matsuoka TA, Katakami N, Shimomura I. Ameliorated pancreatic beta cell dysfunction in type 2 diabetic patients treated with a sodium-glucose cotransporter 2 inhibitor ipragliflozin. Endocr J. 2015;62(1):77-86. doi:10.1507/endocrj.EJ140335

26. Haneda M, Noda M, Origasa H, et al. Japanese clinical practice guideline for diabetes 2016. J Diabetes Investig. 2018;9(3):657-697.

27. Matsuda M, DeFronzo RA. Insulin sensitivity indices obtained from oral glucose tolerance testing: comparison with the euglycemic insulin clamp. Diabetes Care. 1999;22(9):1462-1470. doi:10.2337/ diacare.22.9.1462
28. Sha S, Devineni D, Ghosh A, et al. Pharmacodynamic effects of canagliflozin, a sodium glucose co-transporter 2 inhibitor, from a randomized study in patients with type 2 diabetes. PLoS One. 2014;9(9):e110069. doi:10.1371/journal.pone.0105638

29. Inagaki N, Kondo K, Yoshinari T, Takahashi N, Susuta Y, Kuki H. Efficacy and safety of canagliflozin monotherapy in Japanese patients with type 2 diabetes inadequately controlled with diet and exercise: a 24 week, randomized, double-blind, placebo-controlled, Phase III study. Expert Opin Pharmacother. 2014;15(11):1501-1515. doi:10. 1517/14656566.2014.935764

30. Kohnert KD, Augstein P, Zander E, et al. Glycemic variability correlates strongly with postprandial beta-cell dysfunction in a segment of type 2 diabetic patients using oral hypoglycemic agents. Diabetes Care. 2009;32(6):1058-1062. doi:10.2337/dc08-1956

31. Kramer CK, Choi H, Zinman B, Retnakaran R. Glycemic variability in patients with early type 2 diabetes: the impact of improvement in beta-cell function. Diabetes Care. 2014;37(4):1116-1123. doi:10. 2337/dc13-2591

32. Chen T, Xu F, Su JB, et al. Glycemic variability in relation to oral disposition index in the subjects with different stages of glucose tolerance. Diabetol Metab Syndr. 2013;5:38. doi:10.1186/17585996-5-38

33. Matsuoka TA, Kaneto H, Kawashima S, et al. Preserving Mafa expression in diabetic islet beta-cells improves glycemic control in vivo. J Biol Chem. 2015;290(12):7647-7657.

34. Shimo N, Matsuoka TA, Miyatsuka T, et al. Short-term selective alleviation of glucotoxicity and lipotoxicity ameliorates the suppressed expression of key beta-cell factors under diabetic conditions. Biochem Biophys Res Commun. 2015;467(4):948-954. doi:10.1016/j. bbrc. 2015.10 .038

35. Desouza CV, Bolli GB, Fonseca V. Hypoglycemia, diabetes, and cardiovascular events. Diabetes Care. 2010;33(6):1389-1394. doi:10.2337/dc09-2082

36. Kalra S, Mukherjee JJ, Venkataraman S, et al. Hypoglycemia: the neglected complication. Indian J Endocrinol Metab. 2013;17(5):819834. doi:10.4103/2230-8210.117219

37. Fujita Y, Inagaki N. Update on the efficacy and safety of sodiumglucose cotransporter 2 inhibitors in Asians and non-Asians. $J$ Diabetes Investig. 2019;10(6):1408-1410. doi:10.1111/jdi.13150

\section{Publish your work in this journal}

Diabetes, Metabolic Syndrome and Obesity: Targets and Therapy is an international, peer-reviewed open-access journal committed to the rapid publication of the latest laboratory and clinical findings in the fields of diabetes, metabolic syndrome and obesity research. Original research, review, case reports, hypothesis formation, expert opinion and commentaries are all considered for publication. The manuscript management system is completely online and includes a very quick and fair peer-review system, which is all easy to use. Visit http://www.dovepress.com/testimonials.php to read real quotes from published authors. 